\title{
Pseudoaneurysm of ascending aorta: Post-operative complication
}

\section{Pseudoaneurisma de aorta ascendente: complicación posquirúrgica}

\author{
Leydimar Anmad-Shihadeh ${ }^{1 *}$, Marcos Farrais-Villalba ${ }^{1}$, José L. Martos-Maine ${ }^{1}$, María Facenda-Lorenzo ${ }^{1}$, \\ Patricia Couto-Comba', Luis Álvarez-Acosta', Rafael Llorens-León'², and Julio Hernández-Afonso ${ }^{1}$ \\ ${ }^{1}$ Department of Cardiology, Hospital Universitario Nuestra Senora de la Candelaria; ${ }^{2}$ Department of Cardiac Surgery, Hospiten Rambla de Santa \\ Cruz, Santa Cruz de Tenerife. Canarias, Spain
}

Surgery of the ascending aorta $(A A)$, with the use of tubular prostheses (with the Bentall-De Bono technique since the seventies), has been an alternative for patients with disorders such as annuloaortic ectasia and type $A$ aortic dissection, associated or not with Marfan syndrome. However, it is a procedure with high mortality risks, mainly attributed to late complications, both inherent to the technique and secondary to the procedure (infections or due to diseases of the primitive aorta connective tissue), especially at points where prostheses are connected'.

We present the case of a 57-year-old male patient admitted to our hospital through the imaging unit of the cardiology section due to echocardiographic findings. In his personal history, two AA surgeries stood out, in 2008 (without surgical complications, with Bentall-De Bono technique) and later in 2017 due to severe aortic insufficiency, with Bentall-DE Bono technique, which had post-operative complications with surgical wound infection, dehiscence, and hematoma; on the $6^{\text {th }}$ day after the procedure, he developed fever, with positive blood cultures for Staphylococcus epidermidis, which was treated according to the antibiogram, with good initial evolution. However, on the $18^{\text {th }}$ post-operative day, he presented again with dehiscence of the surgical wound and sternum, which required using the VAC system; control blood cultures were negative. Surgical cleaning and sternal resuture with wound closure were also performed. Intravenous vancomycin was prescribed for 6 weeks and rifampicin $600 \mathrm{mg}$ daily, without complications. Despite this, at 1 month, he was admitted again due to spontaneous hematoma of the surgical wound, with drainage and empirical antibiotic therapy with quinolones being required.

On the current admission, bilateral crackles, jugular engorgement, and pandiastolic murmur were observed on physical examination. Transesophageal echocardiogram showed the left and right ventricle at upper limits of normal, both with preserved contractility; prosthetic tube was visualized in AA as well as aortic mechanical prosthesis with normal gradients but with severe periprosthetic regurgitation (70 ms hemipressure time, $12 \mathrm{~mm}$ contracted vein) (Fig. 1A and B). In the posterior region, at the supravalvular level, an image of dilatation was observed between the wall of the prosthetic tube and the native aorta, with systolic expansion (arrows, Fig. 1C and D). Consequently, an aortic computed

\footnotetext{
Correspondence:

*Leydimar Anmad-Shihadeh

Servicio de Cardiologia

Hospital Universitario Nuestra Señora de Candelaria

Carretera del Rosario, No. 145

Date of reception: 21-01-2018

Date of acceptance: 10-11-2018

DOI: 10.24875/ACME.M19000042

E-mail: shihadehleydimar@gmail.com

Arch Cardiol Mex (Eng). 2019;89(2):171-173

www.archivoscardiologia.com

2604-7063 @ 2018 Instituto Nacional de Cardiología Ignacio Chávez. Published by Permanyer México SA de CV. This is an open access article under the CC BY-NC-ND license (http://creativecommons.org/licenses/by-nc-nd/4.0/).
} 


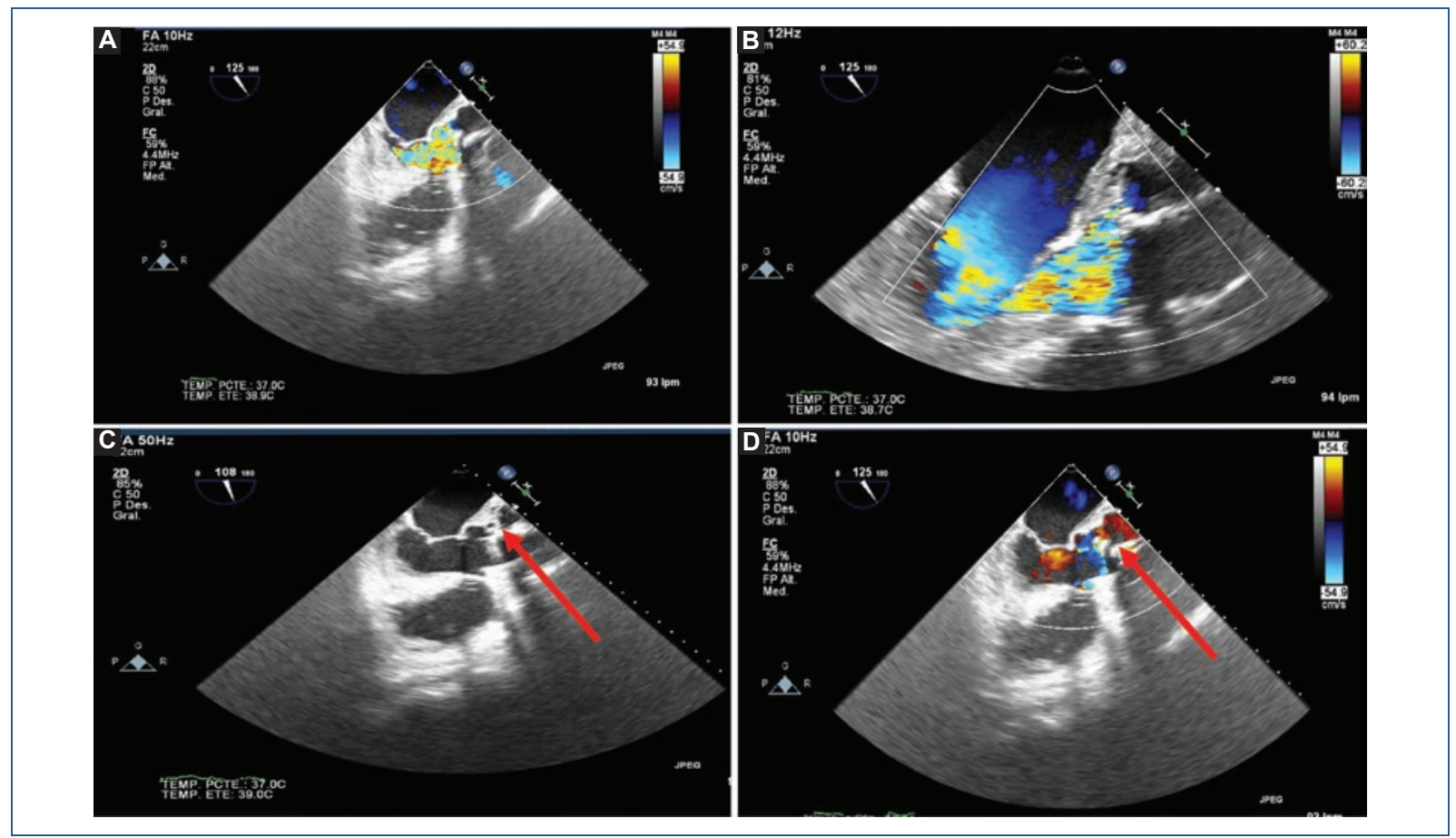

Figure 1. A and B: Severe periprosthetic regurgitation (hemipressure time $70 \mathrm{~ms}$, contracted vein, $12 \mathrm{~mm}$ ); C and D: In the posterior region, at supravalvular level, an image of dilatation is observed between the wall of the prosthetic tube and the native aorta, with systolic expansion (arrows).

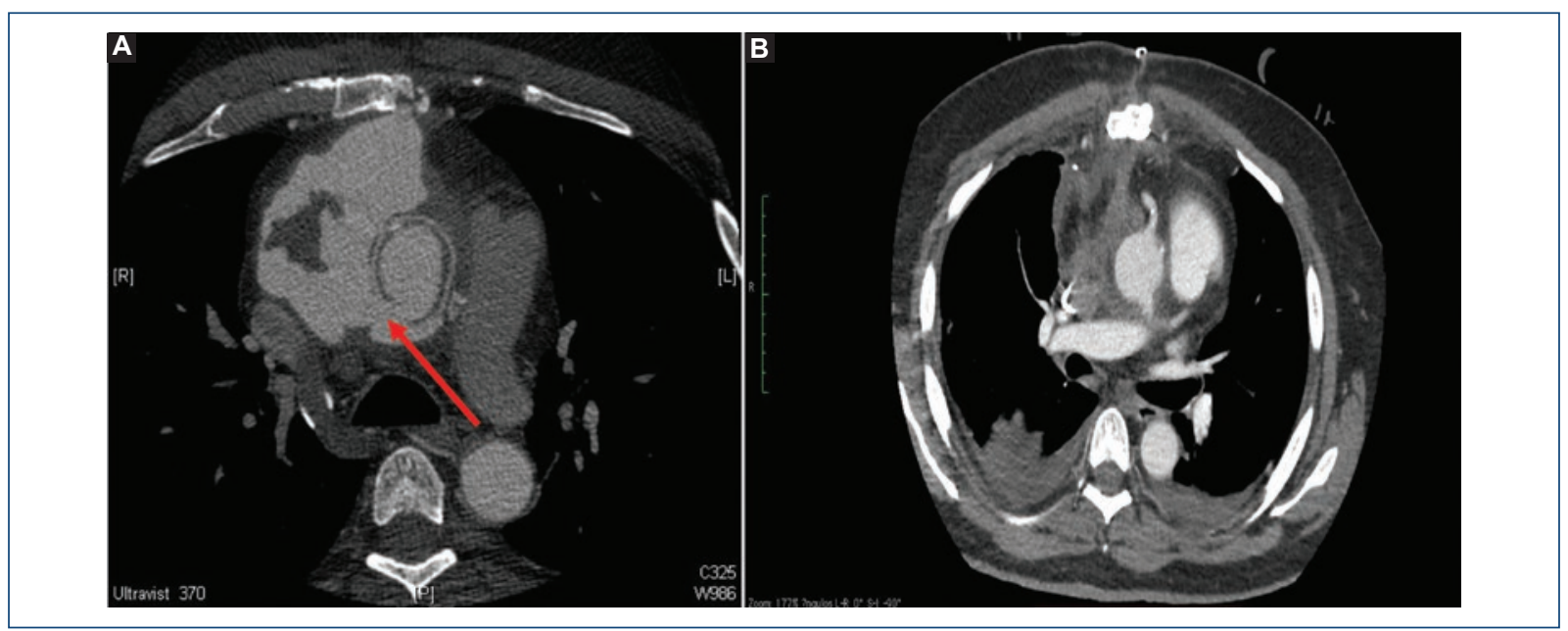

Figure 2. Computed tomography: Large aorta root adjacent collection of $92 \mathrm{~mm} \times 73 \mathrm{~mm} \times 100 \mathrm{~mm}$, with loss of planes with prosthetic tube on its right lateral side and extensive communication with aortic lumen, consistent with large mediastinal hematoma secondary to prosthetic rupture. A: Post-surgical pseudoaneurysm secondary to prosthetic rupture (arrows); B: Post-operative control.

tomography (CT) was performed, which revealed a large aortic root adjacent collection of $92 \mathrm{~mm} \times 73 \mathrm{~mm}$ $\times 100 \mathrm{~mm}$, with loss of planes with prosthetic tube on its right lateral side and extensive communication with aortic lumen, which was consistent with large mediastinal hematoma secondary to prosthetic rupture. With the diagnosis of post-surgical pseudoaneurysm secondary to prosthetic rupture being established by imaging (arrows, Fig. 2A), the patient underwent surgical intervention using the Bentall-De Bono technique 
and was discharged without complications to this day (control post-operative CT, Fig. 2B) ${ }^{2,3}$.

\section{Funding}

None.

\section{Conflicts of interest}

None.

\section{Ethical disclosures}

Protection of people and animals. The authors declare that no experiments have been carried out on humans or animals for this research.
Confidentiality of data. The authors declare that they have followed the protocols of their work center on the publication of patient data.

Right to privacy and informed consent. The authors declare that no patient data appear in this article.

\section{References}

1. Valenzuela García LF, Gallego García de Vinuesa P, Guerrero de Mier M, Beltrán J, Araji O, Barquero Aroca JM. Pseudoaneurisma como complicación de la reconstrucción de aorta ascendente mediante injerto valvulado: dehiscencia perianular simulando una insuficiencia aórtica severa. Rev Esp Cardiol. 1999:52:737-40.

2. Gutiérrez Sánchez JA. Cirugía de la aorta ascendente suprasinusal. Cir Cardiov. 2007:14(4):311-9.

3. Lindefjeld D, Martínez A, Heusser F, Zalaquett R. Cierre percutáneo de pseudoaneurisma post-operatorio de aorta ascendente con dispositivo Amplatzer. Rev Chil Cardiol. 2012;31:63-6. 